Check for updates

Cite this: RSC Adv., 2017, 7, 39465

Received 24th June 2017

Accepted 4th August 2017

DOI: $10.1039 / \mathrm{c} 7 \mathrm{ra07032b}$

rsc.li/rsc-advances

\section{Gas-switchable carbon nanotube/polymer hybrid membrane for separation of oil-in-water emulsions ${ }^{\dagger}$}

\author{
Sinoj Abraham, (D) ab Surjith Kumar Kumaran ${ }^{\mathrm{ab}}$ and Carlo David Montemagno*ab \\ A gas responsive hybrid membrane is fabricated by surface-grafting PDEAEMA on carbon nanotubes. The \\ reversable surface wettabilites switch from hydrophobic to hydrophilic by the introduction of carbon \\ dioxide and nitrogen gases. These can be utilized for oil/water and oil/water emulsion separations. The \\ switchable characteristics of the CNT/PDEAEMA membrane can effectively prevent membrane clogging.
}

Industrial development and oil sand mining has led to dramatically increased levels of environmental pollution. ${ }^{1}$ For example, the steam-assisted gravity drainage extraction of bitumen from oil sands in Alberta, Canada produce tailings during extraction that trap a large amount of emulsion, containing about $30 \%$ bitumen. ${ }^{2}$ To date, many methods have been reported that separate oil from this emulsion, such as adding chemicals to destabilize the emulsion and then separating the coalesced oil by skimming, centrifugation, or coagulation-flocculation. However, these methods have some undesirable components such as low separation efficiency, high operation costs, and the generation of secondary pollutants. ${ }^{3}$ Current technologies for purifying oil-spilled waters or extracting oil from emulsions are typically expensive and specific, so there is a significant need for new approaches. Membrane based oil/water separation technologies are regarded as one of the most promising, low-cost approaches, therefore drawing considerable attention over the last decade. ${ }^{4}$

Inspired by biological systems, researchers have prepared various materials with special wetting surface structures and used them to separate oil/water mixtures. ${ }^{5}$ With the increasing economic development of society, the separation of water/oil mixtures is required for petroleum, chemical products separation, oil spills, and wastewater emissions. For example, oil spills are a significant source of water pollution and have long been a major concern for the general public as well as those in industrial production. This concern stems from the fact that oil spills generated from oil exploration, transportation, or oily sewage emissions are catastrophic for aquatic ecosystems. ${ }^{6}$ In

${ }^{a}$ Ingenuity Lab, 11421 Saskatchewan Drive NW, Edmonton, Alberta, Canada - T6G $2 M 9$

${ }^{b}$ Department of Chemical and Materials Engineering, University of Alberta, Edmonton, Alberta, Canada-T6G 2V4. E-mail: montemag@ualberta.ca

$\dagger$ Electronic supplementary information (ESI) available. See DOI: 10.1039/c7ra07032b natural systems, self-assembled proteins produced hierarchal materials that exhibit chemical and selective transport properties. $^{7}$ A biological cell membrane contains channels e.g. KcsA K ${ }^{+}$ channel, with voltage-responsive gates that can selectively open or close for specific substances to transfer across. ${ }^{8}$ This provides the inspiration for scientists to develop artificial gating channels for self-regulating permeability and selectivity in response to chemical/physical stimuli like changes in light, temperature, $\mathrm{pH}$, and redox. ${ }^{9}$

The stimuli responsive molecules provide a conformational switch to adjust the pore sizes and/or surface properties of the membranes and thus, manage the permeability and selectivity of the membrane. ${ }^{10}$ Meanwhile, the membrane surface properties can also be adjusted by changing the wettability of the substrates. By combining responsive molecules as a coating layer on the membrane substrate, a variety of materials with this switchable wettability have been developed; thus, the affinity between the fouling components and the membrane surface can be weakened to reduce, or even eliminate, the foulants. For example, a temperature-sensitive membrane can be produced by directly grafting poly( $N$-isopropylacrylamide) onto electro spun nano fibres which then exhibit temperature switchable oil/ water wettability. ${ }^{11}$ Similarly $\mathrm{pH}$ and light responsive ultrathin membranes are also utilized for the separation of oil-in-water emulsions. ${ }^{12}$

A recent development in membrane technology is the controlled manipulation of surface wettability by the use of "greenhouse" gases, such as carbon dioxide $\left(\mathrm{CO}_{2}\right)$ and nitrogen $\left(\mathrm{N}_{2}\right)$. The advantages of this development are that these gases are widespread, nontoxic, inexpensive, and a renewable resource, and as such, this has attracted great interest and exploration as to how the gas can act as oil/water on-off switches. ${ }^{13}$ As carbon dioxide $\left(\mathrm{CO}_{2}\right)$ production has been identified as a cause for global climate change, utilization of it for various useful processes can address, to some extent, the inefficiencies of $\mathrm{CO}_{2}$ capture and conversion. ${ }^{14}$ 
In this paper, we report a novel approach to the construction of a hybrid carbon nanotube/poly( $N$-diethylaminopropyl) methacrylate (CNT/PDEAEMA) brush membrane (Fig. 1) with gas-modulated $\left(\mathrm{CO}_{2}\right.$ and $\left.\mathrm{N}_{2}\right)$ wettability for the on/off switchable separation of oil and water also oil/water emulsions. Carbon nanotubes (CNTs) have been widely used in fabricating hybrid composite membranes, as the mechanical stability of the composite membrane is enhanced by CNTs due to their ultrahigh tensile strength, and Young's modulus, high electrical and thermal conductivities, as well as many other functional properties. $^{15}$ This technology is utilized for constructing CNT membranes, and it can only be effective at separating oil-inwater emulsions due to the hydrophobic and hydrophilic surface wetting properties gained by the simple introduction of $\mathrm{CO}_{2} / \mathrm{N}_{2}$ gas. Herein, the incorporation of PDEAEMA endows the ultrathin film around the CNT with a gas switchable hydrophobic-hydrophilic surface, beneficial to the ultrafast separation of oil-in-water emulsions. Notably, PDEAEMA provides the membrane with a chemical valve function by reversibly varying the polymers' conformation, when triggered by gas, results in a tuneable pore radius for switchable permeation properties.

For the creation of hybrid gas sensitive polymer membranes, we first followed our strategy for the synthesis of poly $(N, N$ diethylaminoethyl methacrylate) onto carbon nanotube substrates according to a previous report on surface-initiated atom transfer radical polymerization (SI-ATRP) ${ }^{16}$ the reaction procedures are illustrated in ESI, Fig. S1. $\dagger$ At first, ATRP initiator, isobutryl bromide monolayers were covalently attach on the carbon nanotube. Single-walled CNTs powder and/or MWCNT mats (diameter $4.5 \mathrm{~mm}$ ) were sonicated with a $60 \%$ $\mathrm{HNO}_{3}$ aqueous solution $(40 \mathrm{kHz}$ ) for $30 \mathrm{~min}$ and the mixture was stirred for $24 \mathrm{~h}$ at $80{ }^{\circ} \mathrm{C}$ to create carboxylic acidfunctionalized CNTs. The carboxylic acid-functionalized CNTs were further functionalized with 2-hydroxyethyl 2-bromoisobutyrate to generate a CNT-grafted ATRP initiator. Then, PDEAEMA brushes were grown on the CNT surfaces by using $N, N^{\prime}$-diethylaminoethyl methacrylate (DEAEMA) in a methanol solution $(4: 1)$ in the presence of $\mathrm{CuBr}$, PMDETA, and a CNT macro initiator (0.05\% to DEAEMA) at $80{ }^{\circ} \mathrm{C}$ for $16 \mathrm{~h}$ to yield a CNT grafted PDEAEMA brush. The SI-ATRP technique provides a "graft-from" approach to fabricate a polymer film on a solid surface, and has been applied in the functionalization of CNT surfaces. ${ }^{17}$ This surface-initiated ATRP is versatile and

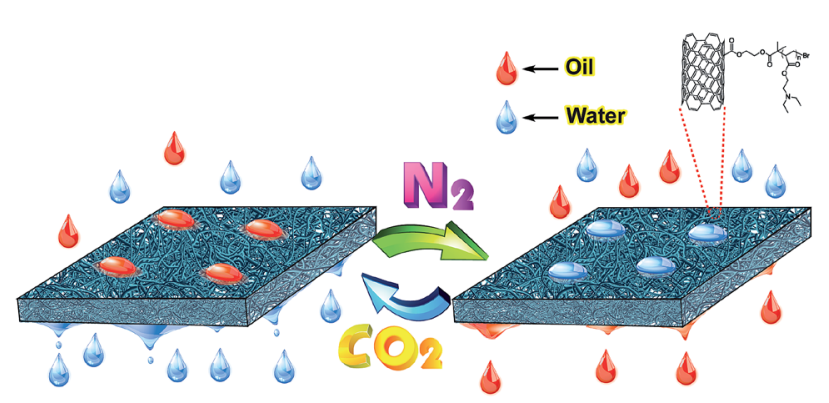

Fig. 1 Schematic illustration of the gas-responsive carbon nanotube/ polymer hybrid membrane and applications for oil/water separation. covalently attaches a wide range of chemical functionalities to the CNT, which allows simple tailoring of the carbon nanotube properties by the incorporation of specific functional groups.

Comparison of the scanning electron microscopy (SEM) images (Fig. 2a and b) and atomic force microscopy (Fig. 2c and d) of the hybrid membranes after the polymerization process with those of the fresh CNT mat, shows that PDEAEMA had been successfully grafted on to the CNT surface by surface initiated polymerization. This was also supported by the FTIR and survey XPS spectrum. The SEM images for the CNT with
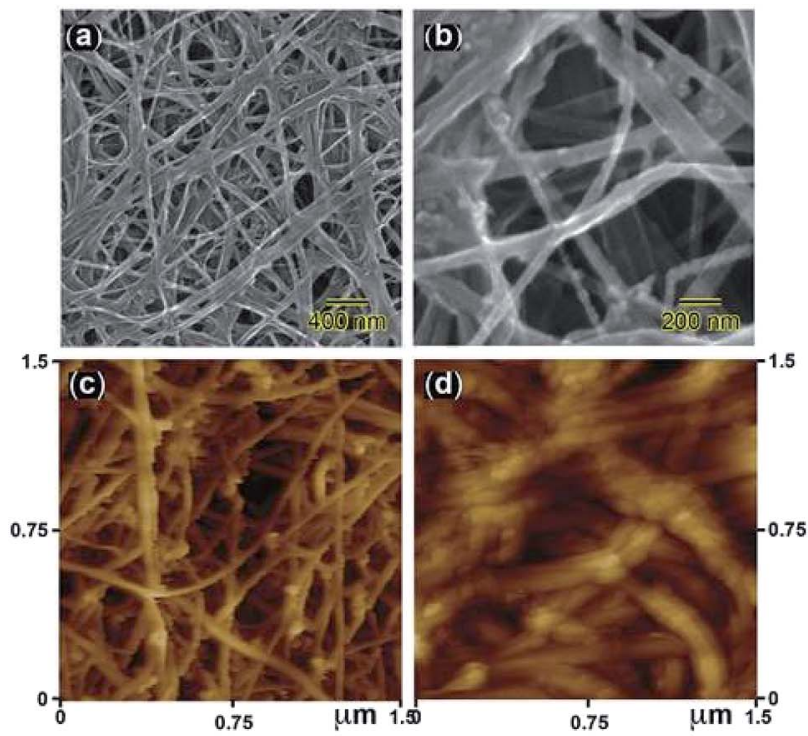

(e)
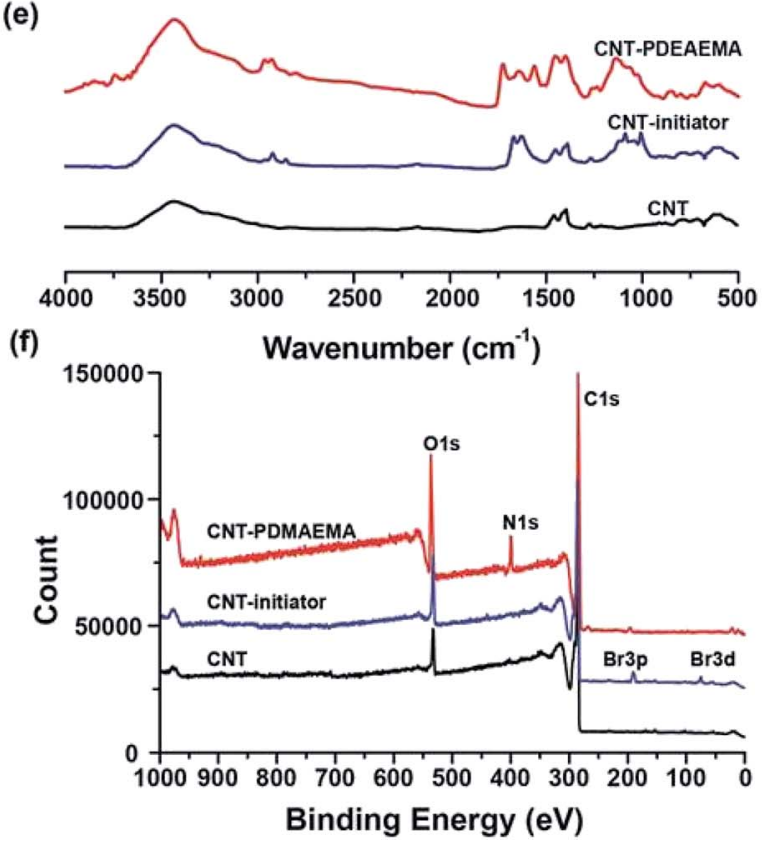

Fig. 2 Scanning electron microscope (SEM) images of bare MWCNT mat (a) and after PDEAEMA polymerization (b) on the membranes. Atomic force microscope images of bare CNT mat (c) and (d) after polymerization of PDEAEMA on the membranes. FTIR spectra (e) and XPS survey spectra (f) of CNT, CNT-grafted initiator and CNT/ PDEAEMA 
PDEAEMA modification (Fig. 2a and b) indicate a clear increase of about $15 \mathrm{~nm}$ in the average diameter of the CNTs relative to the fresh CNTs. AFM images (Fig. 2c and d) also showed an increase in average surface roughness, from $16.2 \mathrm{~nm}$ to $26.8 \mathrm{~nm}$, indicating the improved reliability of this polymerization method. The fresh CNT membrane, macro-initiatormodified CNT membrane, and PDMAEMA modified CNT membranes were examined using FTIR spectra (Fig. 2e) and XPS analysis. The peak at $1725 \mathrm{~cm}^{-1}$ is attributed to the $\mathrm{C}=\mathrm{O}$ bond of the amide group in the CNT modified initiator. The PDMAEMA grafted CNT shows FTIR absorptions at $2944 \mathrm{~cm}^{-1}$ due to the $\mathrm{C}-\mathrm{H}$ symmetric and asymmetric stretching of the $\mathrm{CH}_{3}$ and $\mathrm{CH}_{2}$ groups, and at peaks $2818 \mathrm{~cm}^{-1}$ and $2767 \mathrm{~cm}^{-1}$ from the $\mathrm{C}-\mathrm{H}$ stretching of the $-\mathrm{N}\left(\mathrm{CH}_{3}\right)_{2}$ groups. There is an IR peak at $1723 \mathrm{~cm}^{-1}$ from the $\mathrm{C}=\mathrm{O}$ stretch in the ester group, and a peak at $1150 \mathrm{~cm}^{-1}$ from the $\mathrm{C}-\mathrm{N}$ stretching of the $-\mathrm{N}\left(\mathrm{CH}_{3}\right)_{2}$ groups. XPS data (Fig. 2f) showed the appearance of a $\mathrm{Br} 3 \mathrm{~d}$ peak at $71 \mathrm{eV}$ after macro-initiator modification, and the appearance of the of the $\mathrm{C} 1 \mathrm{~s}$ signal at $285 \mathrm{eV}, \mathrm{N} 1 \mathrm{~s}$ at $400 \mathrm{eV}$, and the $\mathrm{O} 1 \mathrm{~s}$ peak appeared at $532 \mathrm{eV}$ after PDEAEMA grafting. Furthermore, PDMAEMA modification of single-walled CNTs reveals a distinct layer of polymer grafted with an average thickness of about $\sim 9.3 \pm 2.0 \mathrm{~nm}$ from transmission electron microscope (TEM) images (see ESI $\dagger$ ). This SI-ATRP technique can be easily extended to the modification of CNT with other responsive polymers.

The reversible chain conformational changes of MWCNT/ PDEAEMA brushes mat upon passing $\mathrm{CO}_{2}$ and $\mathrm{N}_{2}$ were investigated by static water contact angle measurements. As seen in Fig. 3a, on exposure to a $\mathrm{CO}_{2}$-purged aqueous solution for $30 \mathrm{~min}$, the water contact angle shows a drastic decrease from $113 \pm 5.0^{\circ}$ to $10 \pm 8.0^{\circ}$, indicative of polymer brush hydration. After passing $\mathrm{N}_{2}$ gas through the MWCNT mat membrane for $10 \mathrm{~min}$, the initial contact angle was recovered, which suggests the loss of water from the polymer brushes and their collapse upon $\mathrm{CO}_{2}$ removal, leads to the deprotonation of PDEAEMA. The experiments were repeated several times (Fig. 3b), showing the switching of the water contact angle with alternate bubbling with $\mathrm{CO}_{2}$ and $\mathrm{N}_{2}$ gases. The gas-controlled, polymer brush grafted, SWCNT-water dispersibility was further depicted in the photographs (Fig. 3c), where the suspension of SWCNT/ PDEAEMA showed excellent water dispersibility when bubbled with $\mathrm{CO}_{2}$ for $30 \mathrm{~min}$. No obvious precipitation was observed when it was stored for several days in a tightly closed vial, suggesting that PDEAEMA had successfully conjugated on the surface of the CNTs. After bubbling with $\mathrm{N}_{2}$, the CNT/PDEAEMA was quickly precipitated due to the ionization of PDEAEMA being suppressed, thus decreasing electrostatic repulsion between the SWCNT/PDEAEMA. The advantage of gas responsive membranes compared to a conventional pH-responsive membrane is that it functions without using strong chemicals (such as acid and base) to change $\mathrm{pH}$ and generally requiring repeated addition of these chemicals into the solution, producing chemical wastes such as excessive salts. Besides its switchable wettability, the simultaneous hydrophobicity and hydrophilicity makes the CNT/PDEAEMA membrane a very promising candidate for oil/water separations. To test that, we

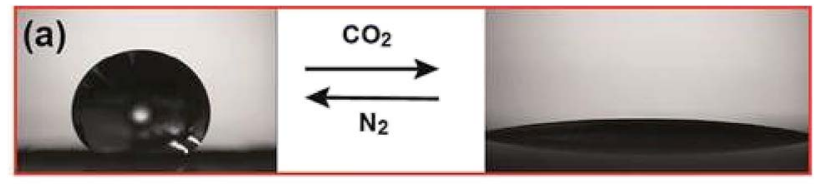

(b)

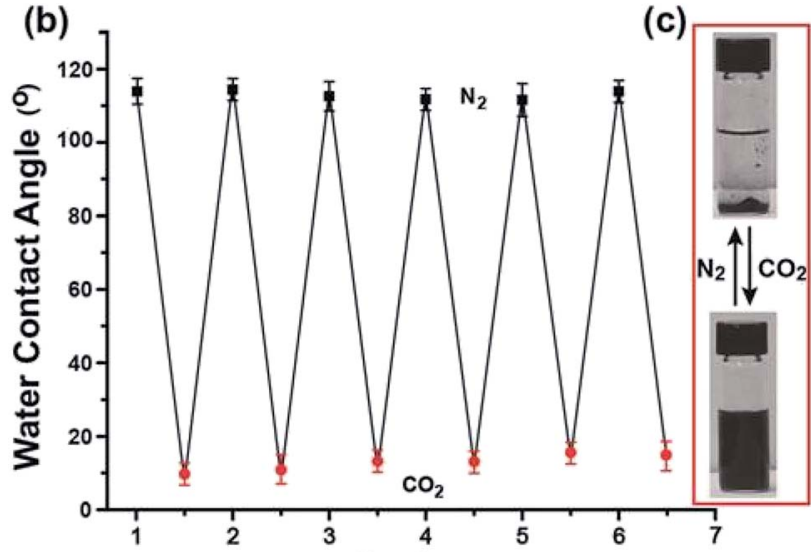

(d)

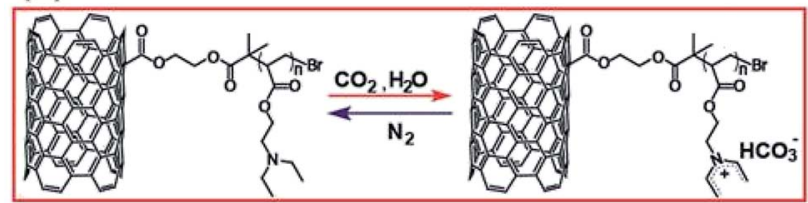

Fig. 3 Water droplets on a MWCNT/PDEAEME mat surface upon introduction of $\mathrm{CO}_{2}$ and $\mathrm{N}_{2}$ gases (a); cyclic experiments illustrating reversible switching of contact angle (CA) upon alternative introduction of images of $\mathrm{CO}_{2}(\mathbf{O})$ and $\mathrm{N}_{2}$ (O) gases (b); photographs of powdered SWCNT/PDEAEMA dispersions in water upon introduction of images of $\mathrm{CO}_{2}$ and $\mathrm{N}_{2}$ (c); schematic illustration for demonstrating mechanism of gas responsive amphiphilicity by introduction of $\mathrm{CO}_{2}$ and $\mathrm{N}_{2}$ of CNT/PDEAEMA membrane (d).

prepared $4.9 \mathrm{~cm}^{2} \mathrm{CNT} / \mathrm{PDEAEMA}$ polymer membranes with a thickness of $1.5 \mathrm{~mm}$ (it is quite possible to realize larger scale industrial production by further enlarging the equipment). As expected, the as-prepared CNT/PDEAEMA membranes, which combine gas-switchable wettability and high porosity, demonstrated efficient separation for oil/water mixtures. The responsive mechanism (Fig. 3d) is typically a variation of $\mathrm{pH}$ control and is the result of the reaction of $\mathrm{CO}_{2}$ with a functional group. At initial state, the CNT/PDEAEMA hybrid membrane surface is insoluble (hydrophobic state) in water, because the polymeric tertiary amines are more hydrophobic in their neutral form. By passing $\mathrm{CO}_{2}$ through the solution, the tertiary amine groups in PDEAEMA react with $\mathrm{CO}_{2}$ in an aqueous medium; forming charged ammonium bicarbonate salts. ${ }^{18}$ This renders the PDEAEMA brushes soluble in water, thus adopting the chainextended state. Subsequently, passing $\mathrm{N}_{2}$ through the solution can remove $\mathrm{CO}_{2}$ and bring the PDEAEMA brushes back to the insoluble state. Such $\mathrm{CO}_{2}$ switchable water solubility can be repeated many times and, as mentioned above, without the addition of any chemicals that could remain in the solution. As a proof of concept, the oil-water separation experiment procedure was performed as shown in Fig. 4. The CNT/PDEAEMA membranes were fixed between two glass tubes placed 
(a)

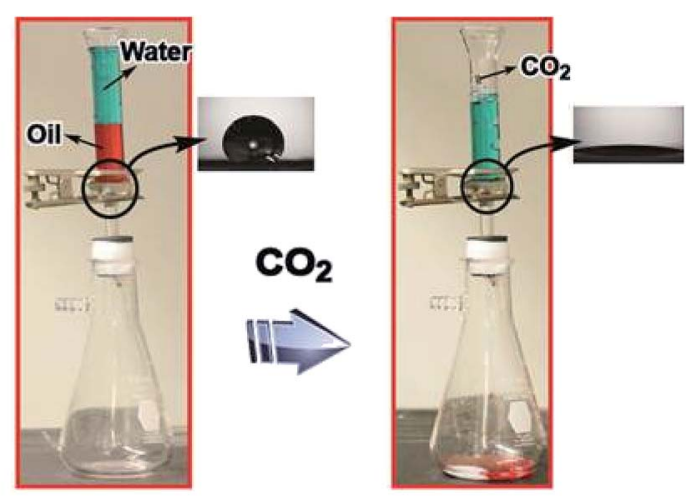

(b)

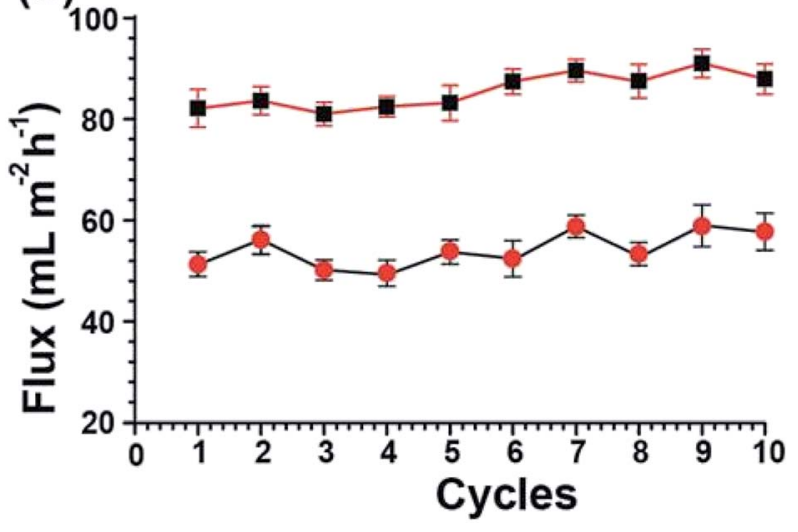

Fig. 4 Oil/water separation using switchable gas responsive membranes, the water and oil were dyes by methyl blue and oil red respectively. (a) Photograph of separation apparatus with $20: 20 \mathrm{v} / \mathrm{v}$ chloroform (oil red dyed) and water (methylene blue dyed). At initial stage, chloroform permeated easily through membrane (hydrophobic state). Upon $\mathrm{CO}_{2}$ bubbling, the CNT/PDEAEMA became hydrophilic thus initiate the water permeation. (b) Water ( $(\bullet)$ and oil ( $\boldsymbol{\square}$ ) permeation flux with several repeated cycle of $\mathrm{CO}_{2} / \mathrm{N}_{2}$ bubbling of CNT/PDEAEMA membranes.

vertically and a $20 \mathrm{~mL}$ mixture of oil (dichloromethane dyed with oil red) and water ( $50 \% \mathrm{v} / \mathrm{v}$, dyed with methylene blue) was poured onto the upper glass tube. The oil quickly permeated through the membranes and dropped into the beaker below while the water was retained above the membranes due to the hydrophobicity of the CNT/PDEAEMA membrane. Gravity was used to force the separation. After the oil separation, the water was bubbled with $\mathrm{CO}_{2}$ and collected in the beaker below for further analysis. A video of the entire gas switchable permeation of organic solvent and water can be seen in the ESI. $\dagger$

The oil/water separation ability of the CNT/PDEAEMA membranes was quantitatively estimated by calculating oil/ water separation efficiency $\left(\eta_{\mathrm{s}}\right)$, which was defined to be the ratio between the weight of collected water after oil/water separation and that of original water before separation. It is worth noting that the ubiquitous water loss induced by the water adhesion on the surface of the glass vessels during the oil-water separation process was not considered for the calculation of $\eta_{\mathrm{s}}$. The separation efficiency of gas responsive CNT/ PDEAEMA membranes achieved high oil/water separation with a high $\eta_{\mathrm{s}}$ value of around $92.7 \%$. Fig. $4 \mathrm{~b}$ shows that the water permeates through the sample with a flux of $\sim 58 \mathrm{~mL} \mathrm{~m}^{-2} \mathrm{~h}^{-1}$ and the chloroform solvent is $\sim 90 \mathrm{~mL} \mathrm{~m}^{-2} \mathrm{~h}^{-1}$. The atmospheric pressure is used here to pressurize the system, which implies the lower permeation flux for these membranes.

We then tested the separation performance of the gassensitive membranes by making a highly stabilized emulsified oil/water (dodecane-in-water) mixture and using it as a representative emulsion to permeate the membranes. The emulsion can maintain a milky white colour for at least several days without any disturbance. The flux change of CNT/PDEAEMA with a permeating volume of an oil-in-water emulsion under $\mathrm{CO}_{2}$ bubbling has been monitored, as shown in Fig. 5a. The membranes experience a fast decline of flux when compared to free oil/water mixtures. It is well known that it is more difficult to separate oil-in-water emulsions owing to the surfactants added for emulsion formation. At first, the feed emulsion solution contained $\sim 720 \pm 150 \mathrm{~nm}$. Then, a surfactant stabilized oil-in-water emulsions was poured into the filtration apparatus and was filtered under bubbling $\mathrm{CO}_{2}$. As shown in Fig. 5b, emulsion droplets disappeared and pure water was quickly permeated though the membrane, while the oil was retained above the membrane. Optical microscopy images and dynamic light scattering (DLS) data (Fig. 5c) suggest the separation effectiveness by comparing the feed and the filtrate.

The hierarchical-structured surface of the CNT/PDEAEMA membrane adsorbs the surfactant-stabilized emulsion. While $\mathrm{CO}_{2}$ was bubbled in the emulsion, the PDEAEMA became hydrophilic as a result of the conformational transition of the polymer brush from a collapsed state to an extended state. Intermolecular forces between the hydrophilic polymer chains

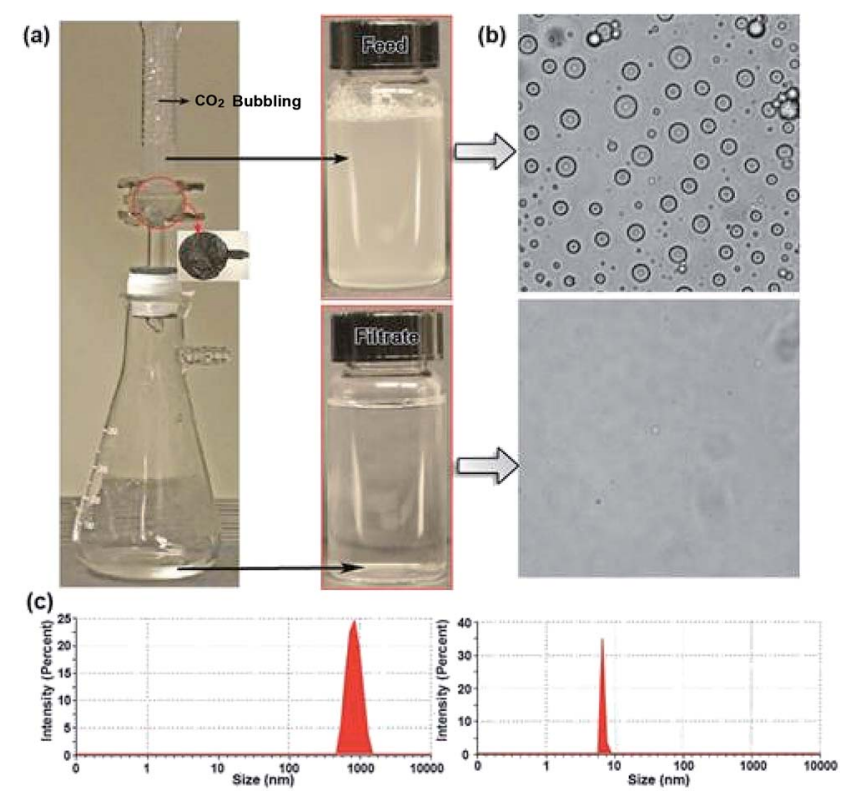

Fig. 5 Oil-in-water emulsion separation using switchable gas responsive membranes: A photograph of separating dodecane-inwater emulsion apparatus and feed and filtrate (a); optical microscope images (b) and DLS data of dodecane-in-water emulsion (c) before and after filtration were water selectively permeates through the CNT/ PDEAEMA membrane by bubbling with $\mathrm{CO}_{2}$ gas. 
and the hydrophilic surface of the emulsified oil-in-water droplets acted as the driving forces for demulsification. These intermolecular forces, including hydrogen bonding and van der Waals forces, then broke the stable emulsions. The straining of the emulsified droplets during the so-called absorption-extrusion process also increased the destabilization of the emulsion. Subsequently, by passing $\mathrm{N}_{2}$ through the oil-in water emulsion, the dissolved $\mathrm{CO}_{2}$ was removed and the PDEAEMA brush switched back to the collapsed state and demulsification ceased. The emulsion that had been stabilized by Tween-20 contained plenty of globules with diameters ranging from several micrometers to hundreds of micrometers. Therefore, the macro and nano hierarchical-structured surface of the CNTPDEAEMA membrane could contact sufficiently with these emulsified droplets. The appropriate pore size effect between the emulsion and the hybrid membrane also lead to the effective separation of the emulsion. Two-dimensional (2D) membranes were highly efficient for emulsion and could be applied to industrial sewage treatment, due to their continuous processing ability. This hybrid-CNT/PDEAEMA membrane is similar to a demulsifier, in that the hydrophilic membranes function well with oil-in-water emulsions and is interchangeable by gas stimuli during the filtration process. Good wettability between the hydrophilic membrane and the oil-in-water emulsion results in the formation of hydrogels in the pore. In addition, the switchable characteristics of the CNT/PDEAEMA membrane will effectively stop the clogging of membrane pores.

In this work we have demonstrated a novel stimuliresponsive hybrid membrane that exhibits gas-controllable switching between extended (hydrophobic) and collapsed (dehydrated) chain conformations. The switching performance could be repeated for many cycles at room temperature without adding hazardous chemicals into the solution. This hybrid CNT/PDEAEMA membrane was further utilized for oil/water separation and oil-in-water emulsions, with $>92 \%$ demulsification efficiency. This gas induced stimuli-responsive membrane could play a major role in carbon capture and utilization processes where the $\mathrm{CO}_{2}$ could be used in an economically viable area. The gas induced stimuli-responsive membranes have enormous scientific and technological interest because of their easy and robust control by gases, which offer many possibilities to develop new smart materials and devices for various applications.

\section{Conflicts of interest}

There are no conflicts to declare.

\section{Acknowledgements}

The authors would like to acknowledge the National Institute for Nanotechnology and Nanofab of University of Alberta for the equipment and instrumentation. The authors further acknowledge Tortech Nano fibers for providing the carbon nanotube mats for functionalization studies. This work was supported by the Province of Alberta, Alberta Innovates
Technology Futures (AITF) and the National Institute for Nanotechnology.

\section{References}

1 K. P. Timoney and P. Lee, Open Conserv. Biol. J., 2009, 3, 6581.

2 (a) R. M. Butler, in Horizontal Wells for the Recovery of Oil, Gas and Bitumen, Petroleum Society, Canada Institute of Mining, Metallurgy and Petroleum (CIM), Issue 2, Petroleum Society Monograph, Westmount, Quebec, Canada, 1994, pp. 169199; (b) Y. Long, T. Dabros and H. Hamza, Fuel, 2002, 81, 1945-1952.

3 A. K. Kota, G. Kwon, W. Choi, J. M. Mabry and A. Tuteja, Nat. Commun., 2012, 3, 1025.

4 (a) Z. X. Xue, S. T. Wang, L. Lin, L. Chen, M. J. Liu, L. Feng and L. Jiang, Adv. Mater., 2011, 23, 4270-4273; (b) J. Gu, P. Xiao, J. Chen, J. Zhang, Y. Huang and T. Chen, ACS Appl. Mater. Interfaces, 2014, 6, 16204-16209.

5 (a) Z. Xue, Y. Cao, N. Liu, L. Feng and L. Jiang, J. Mater. Chem. A, 2014, 2, 2445; (b) A. Tuteja, W. Choi, M. Ma, J. M. Mabry, S. A. Mazzella, G. C. Rutledge, G. H. McKinley and R. E. Cohen, Science, 2007, 318, 1618.

6 (a) M. A. Shannon, P. W. Bohn, M. Elimelech, J. G. Georgiadis, B. J. Marinas and A. M. Mayes, Nature, 2008, 452, 301-310; (b) J. Aurell and B. K. Gullett, Environ. Sci. Technol., 2010, 44, 9431-9437.

7 U. G. K. Wegst, H. Bai, E. Saiz, A. P. Tomsia and R. O. Ritchie, Nat. Mater., 2014, 14, 23-36.

8 Y. Jiang, A. Lee, J. Chen, M. Cadene, B. T. Chait and R. MacKinnon, Nature, 2002, 417, 523-526.

9 (a) L.-Y. Chu, T. Niitsuma, T. Yamaguchi and S. Nakao, AIChE J., 2003, 49, 896-909; (b) Z. Cheng, J. Wang, H. Lai, Y. Du, R. Hou, C. Li, N. Zhang and K. Sun, Langmuir, 2015, 3, 1393-1399; (c) M. Yang, R. Xie, J.-Y. Wang, X.-J. Ju, L.-H. Yang and L.-Y. Chu, J. Membr. Sci., 2010, 355, 142150; (d) D. Tian, X. Zhang, Y. Tian, Y. Wu, X. Wang, J. Zhai and L. Jiang, J. Mater. Chem., 2012, 22, 19652-19657; (e) S. K. Kumar and J. D. Hong, Langmuir, 2008, 24, 4190-4193.

10 Z. Liu, W. Wang, R. Xie, X. J. Ju and L. Y. Chu, Chem. Soc. Rev., 2016, 45, 460-475.

11 Y. F. Wang, C. L. Lai, H. W. Hu, Y. Liu, B. Fei and J. H. Xin, $R S C A d v ., 2015$, 5, 51078.

12 (a) Y. Ito, S. Nishi, Y. S. Park and Y. Imanishi, Macromolecules, 1997, 30, 5856-5859; (b) Y. Cao, N. Liu, C. Fu, K. Li, L. Tao, L. Feng and Y. Wei, ACS Appl. Mater. Interfaces, 2014, 6, 2026-2030; (c) L. Hu, S. Gao, X. Ding, D. Wang, J. Jiang, J. Jin and L. Jiang, ACS Nano, 2015, 9, 4835-4842.

13 (a) D. Han, X. Tong, O. Boissiere and Y. Zhao, ACS Macro Lett., 2012, 1, 57-62; (b) S. Lin and P. Theato, Macromol. Rapid Commun., 2013, 34, 1118-1133; (c) D. Han, O. Boissiere, S. Kumar, X. Tong, L. Tremblay and Y. Zhao, Macromolecules, 2012, 45, 7440-7445; (d) H. L. Che, M. Huo, L. Peng, T. Fang, N. Liu, L. Feng, Y. Wei and J. Y. Yuan, Angew. Chem., 2015, 127, 9062-9066; (e) H. Y. Yin, A. L. Bulteau, Y. J. Feng and L. Billon, Adv. 
Mater. Interfaces, 2016, 3, 1500623; $(f)$ Z. Guo, Y. Feng, Y. Wang, J. Wang, Y. Wu and Y. Zhang, Chem. Commun., 2011, 47, 9348-9350; $(g)$ Z. Guo, Y. Feng, S. He, M. Qu, H. Chen, H. Liu, Y. Wu and Y. Wang, Adv. Mater., 2013, 25, 584-590.

14 J. Olivier, G. J. Maenhout and P. Jahw, Trends in Global $\mathrm{CO}_{2}$ Emissions: 2012 Report, PBL Netherlands Environmental Assessment Agency; Ispra: Joint Research Centre, The Hague, Netherlands, 2012.

15 (a) A. Gusev and O. Guseva, Adv. Mater., 2007, 19, 2672-2676; (b) M. R. Falvo, G. J. Clary, R. M. Taylor II, V. Chi, F. P. Brooks
Jr, S. Washburn and R. Superfine, Nature, 1997, 389, 582; (c) J. K. Holt, H. G. Park, Y. Wang, M. Stadermann, A. B. Artyukhin, C. P. Grigoropoulos, A. Noy and O. Bakajin, Science, 2006, 312, 1034-1037.

16 H. Kong, C. Gao and D. Y. Yan, J. Am. Chem. Soc., 2004, 126, 412-413.

17 D. Baskaran, J. W. Mays and M. S. Bratcher, Angew. Chem., Int. Ed., 2004, 43, 2138-2142.

18 (a) S. Kumar, X. Tong, Y. L. Dory, M. Lepage and Y. Zhao, Chem. Commun., 2013, 49, 90; (b) H. Jiang, E. Wang and J. Wang, RSC Adv., 2015, 5, 35622-35630. 